\title{
HBIM ORIENTED TOWARDS THE MASTER PLAN OF THE CHARTERHOUSE OF JEREZ (CÁDIZ, SPAIN)
}

\author{
M. Castellano-Román ${ }^{1 *}$, F- Pinto-Puerto ${ }^{2}$ \\ ${ }^{1}$ University of Seville, Dept. of Architectural Graphical Expression, Strategies of Heritage Knowledge (HUM799), Av. Reina \\ Mercedes, 41012 Seville, Spain - manuelcr@us.es \\ ${ }^{2}$ University of Seville, Institute of Architecture and Building Science (IUACC), Av. Reina Mercedes, 41012 Seville, Spain - \\ fspp@us.es
}

Commission II, WG II/8

KEY WORDS: HBIM, BIM, Heritage Management, Architectural Heritage, Charterhouse of Jerez.

\begin{abstract}
:
This paper is focused on the possibilities of Heritage Building Information Modelling HBIM to enhance the strategic planning of large monuments ensembles in a Master Plan. The study case is the Charterhouse of Jerez (Cádiz, Spain), a monument acknowledged with the highest level of legal protection since 1856. Its HBIM model, developed with a Level of Knowledge LOK200, provides appropriate alphanumerical and graphical outputs for strategic decision-making on the major guidelines of heritage management: research, protection, conservation and dissemination. This LOK200 HBIM model emerges from the integration of graphic information produced with different techniques, from historic plans to photogrammetric surveys. In relation to research, the architectural analysis required to generate the HBIM model has defined its constructive elements and spaces, its construction process and the higher heritage potential areas. In addition, the synthetic views produced from the model have allowed unexpected relationships and conclusions about the monument. In relation to protection, a precise delimitation of the monument site and its surroundings have been defined. Furthermore, areas with different levels of vulnerability have been characterized. In relation to conservation, the severity of the damages in the main structures and the urgency of the interventions have been defined. In relation to dissemination, the relationship between its current religious use and the odds for public visit have been presented.
\end{abstract}

\section{INTRODUCTION}

In recent years, the use of BIM methodology in the field of cultural heritage has accumulated a wide set of experiences, with deep differences in objectives, methodologies and results. Some of them deals with the modelling of historical buildings as a particular case of the modelling of complex geometries associated with parametric design (Aubin, 2013), placing this line of work within the context of the techniques of virtual reconstruction and visualization of historic buildings, whose reference document is the so-called Principles of Seville (LópezMenchero and Grande, 2011), based on its direct precedent, the London Charter.

Many others have attended to the semiautomatic generation of high geometric accurate models based on digital captures of point clouds (Murphy et al., 2011) (Brusaporci, 2015) (Garagnani and Manferdini, 2013).

However, BIM methodology offers the Level of Development concept, which offers the possibility of early stages with a basic definition of the geometry and the information. That has suggested the adaptation of the LOD concept in the field of cultural heritage named as Level of Knowledge LOK and, as a consequence, the adaptation of the geometric and information characterization to the purpose of the model (Castellano Román and Pinto Puerto, n.d.) Thus, in this HBIM approach, the priority is not the achievement of high precision three-dimensional modelling, but rather the exploration of BIM possibilities as regards architectural survey (Figure 1).

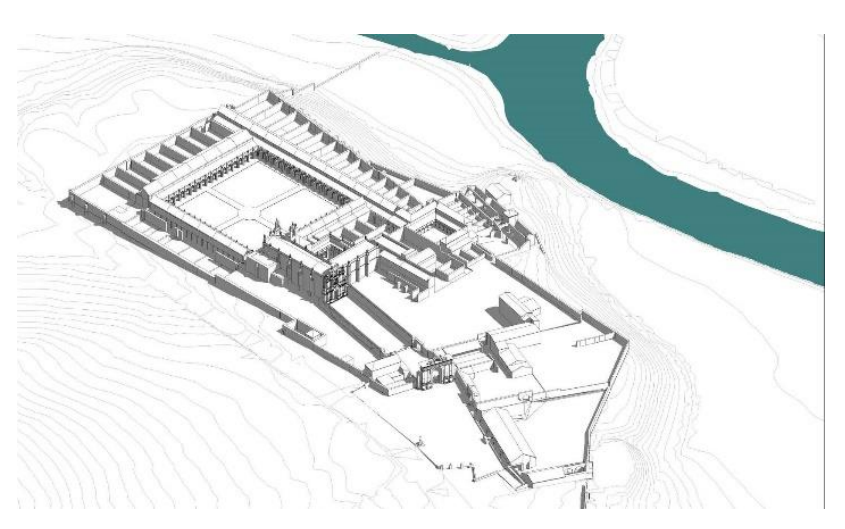

Figure 1: HBIM Charterhouse of Jerez, phase 07 (1769-1835)

In this sense, a case that is relevant for this research is the Aqueduct of Aguas Libres in Lisbon. This work proposes a methodological option that postpones the acquisition of maximum precision by the model for the geometric definition of the elements, which can be accessed later, for the sake of an integral approach to the heritage asset as a whole that addressed the urgency for its evaluation in order to prevent loss (Rua and Gil, 2014). Another case with similar conceptual foundations is that developed in the Italica Archaeological Complex, where the site is treated in its entirety by establishing an active cartographic base (Pinto et al., 2011) for the systematization of heritage information of the complex, using BIM systems for the

\footnotetext{
* Corresponding author
} 
management of diagnosis and conservation (Pinto et al., 2010). From an initial basic definition, but which covers the entire complex, the response to the requirements proposed for its Master Plan are addressed. Subsequently, progress is made in the level of development of a defined area, with a specific project for the Casa de Hylas, in which photogrammetric accuracy was achieved (Angulo Fornos, 2009). Finally, the case of the Church of San Pedro de Arcos de la Frontera (Castellano Román, 2013). In this work, the generation of the model and the information structure linked to it were focused on research and legal protection through registration as an asset of cultural interest.

\subsection{Case study}

The asset selected for study is the Charterhouse of Nuestra Señora de la Defensión in Jerez de la Frontera, a monastery located five kilometres from the urban centre, occupying a confined area between the Jerez expressway to Medina Sidonia and the Guadalete River (Figure 2). Its architectural configuration is articulated around the monastic nucleus, which is surrounded by different structures of different origins and functions, which result from its long historical process.

The foundation was constructed in the 15 th century and its constructive evolution develops throughout the 16th and 17th centuries through the end of the 18th century. During the 19th and 20th centuries, the Charterhouse of Jerez experienced ruin, plunder and neglect with respect to its cultural value, protection and conservation.

The result of these historical upheavals is the Asset of Cultural Interest that survives today and in which, far from resolution of the confrontation between loss and conservation of its heritage value, gaps remain in management, unworthy of its heritage value and in the state of knowledge that the disciplines concerned in terms of cultural heritage have reached, seriously threatening its survival. Its unquestionable heritage value and its huge extension turns it into a complex case of heritage management.

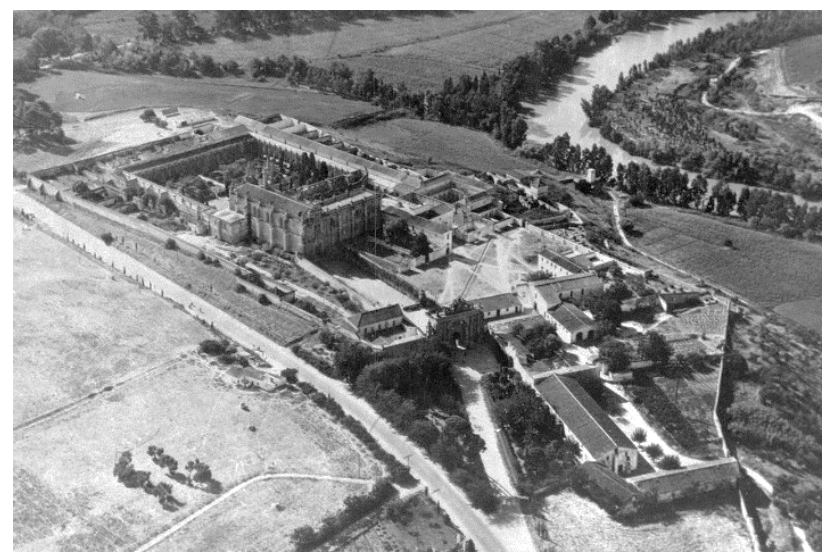

Figure 2: Charterhouse of Jerez. Aerial photography in the middle of the 20 th century.

\subsection{Methodology}

The methodology for the generation of an HBIM model of the Charterhouse of Jerez, oriented towards the strategic planning of its heritage management, has been developed in four overlapped stages, whose interactions have enhanced its contents.

The first stage has been the documentary sources review in order to produce an information repository, as comprehensive as possible. This repository has provided the heritage data required to model the monastery. It has been called Heritage Building Information Repository, HBIR. The second stage has been the use of the building itself as a documentary source, reading the tangible traces that confirm or refute the data obtained from the documents. The third stage has been the architectonical analysis, oriented towards the interpretation of the design and building processes and the architectonical space concepts implied in them. The fourth stage has been the generation of the HBIM model, testing the building process of the Charterhouse of Jerez virtually.

\section{BASES FOR A MASTER PLAN OF THE CHARTERHOUSE OF JEREZ.}

The Spanish National Plan on Abbeys, Monasteries and Convents, PNAMC, addresses the requirement of a Master Plan in order to establish the major guidelines for the heritage management of the Charterhouse of Jerez. Once the HBIM model of the Charterhouse of Jerez has been generated at a LOK200 Level of Knowledge and the Heritage Building Information Repository is prepared, the foundation has been laid for this strategic document (Castellano Román and Pinto Puerto, n.d.).

This research does not aim the automatic generation of a Master Plan, as this type of document is based on the interests of a wide spectrum of stakeholders: technicians, Cultural Administration, owners and usufructuaries, which have not been directly involved in this research. Furthermore, they require a wide and deep series of diagnostic works unaffordable in the context of this research. Nevertheless, the proposed methodology offers graphic and alphanumeric information for strategic decision-making on the major lines of heritage management: research, protection, conservation and dissemination.

\subsection{Research}

In relation to research, two processes have to be taken into account. Firstly, the architectural analysis required to generate the HBIM model has defined its constructive elements and spaces, its construction process and the higher heritage potential areas.

Secondly, once the HBIM model is available, the synthetic views produced from the model have allowed unexpected relationships and conclusions. For example, the model has made possible a view showing the extensive impact of demolitions and structural damages once the monastery was abandoned 1835, making possible a new understanding of its evolution (Figure 3).

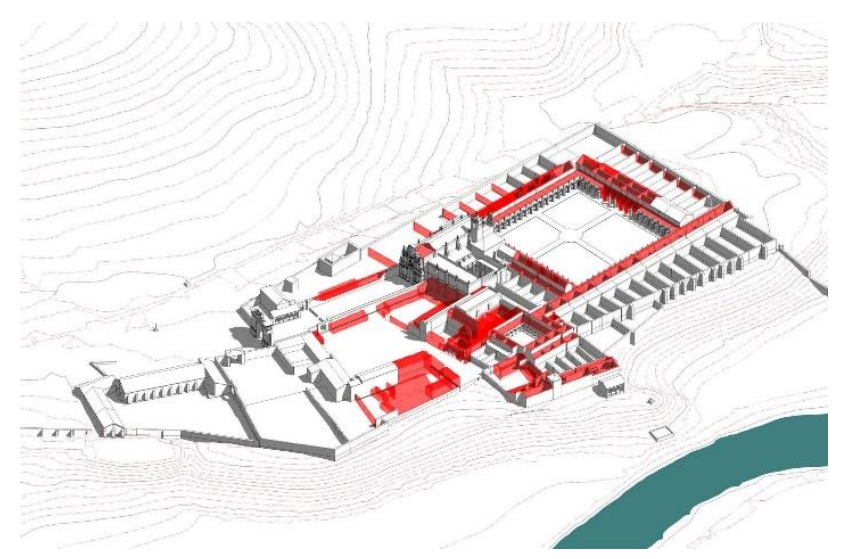

Figure 3: Ruins and demolitions scope after the secularization of the monastery. HBIM Charterhouse of Jerez, phase 08:

Secularization (1835-1875) 
The comprehensive heritage interpretation of the Charterhouse of Jerez has enabled a classification of the areas of the monastery according to their potential to produce significant data refusing, completing or inspiring new research. The methodologies and tools to be applied to verify each hypothesis should be determined in the intervention projects: ground penetrating radar, magnetic measurements, archaeological excavation, etc. In this point, it is more relevant to define the questions to be asked about the monument than the technology to be used to answer them.

Therefore, the concept "heritage potential" has been defined as an estimation of the quantity and quality of heritage information that can be achieved in any area of the cultural asset. This concept has been codified as an information parameter associated to the elements of the HBIM model. Two settings are predefined to "heritage potential" parameter: "generic" or "specific". "Generic" value has been the most widespread, as it means an alignment with the heritage potential of the monument as a whole. On the other hand, "Specific" value has been allocated in areas poorly studied but with high expectations of knowledge growth (Figure 4) .

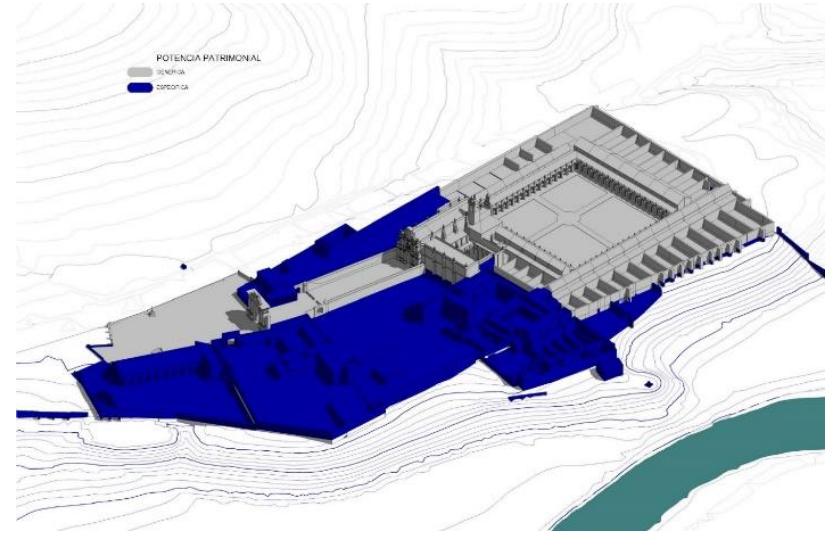

Figure 4: Heritage Potential view. HBIM Charterhouse of Jerez, phase 15, Sisters of Bethlehem (2000-...)

\subsection{Protection}

Although the Charterhouse of Jerez is a monument acknowledged with the highest level of legal protection since 1856 , or perhaps precisely for this reason, its legal protection lacks an updated definition and a precise delimitation of the monument site and its surroundings. In addition, there are several stakeholders concerned by the monument, especially the Spanish State as owner, the Catholic Church as usufructuary and the Regional Government of Andalusia, which is responsible for heritage issues. This circumstance has made even more complex and controversial than usual any decision-making dealing with the protection of the Charterhouse. In these circumstances, townplanning rules of Jerez de la Frontera and its Archaeological Chart (González Rodríguez, 2008) are the most effective legal framework for its protection.

Hence, an updated identification of the Charterhouse of Jerez as an Asset of Cultural Interest is necessary. The elements of the HBIM model have included a parameter to identify its belonging to the monument complex itself or its surroundings. A precise delimitation of the monument site and its protection surroundings was defined, including not only the most recognisable buildings of the monument complex but also those other buildings and surroundings which complete its heritage value in a comprehensive sense: artistic, historical, ethnographical, territorial, social-economic, in other words, as a part of a cultural landscape (Figure 5).

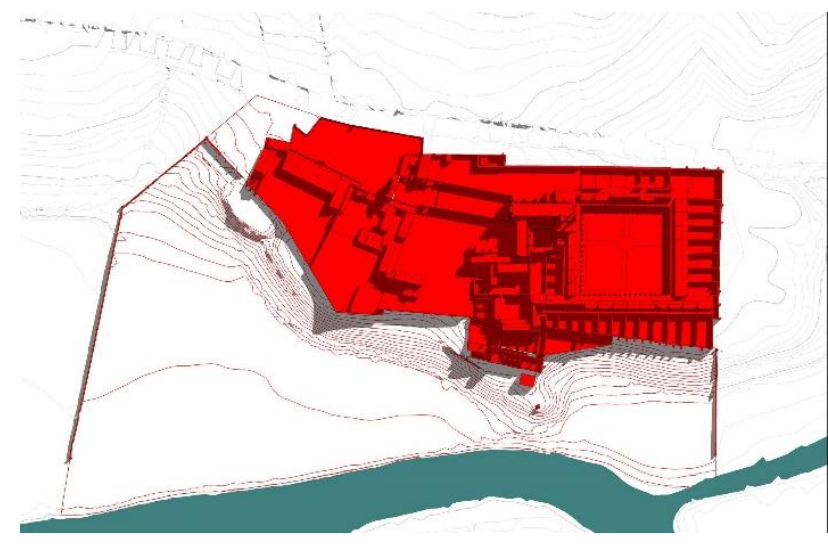

Figure 5: Delimitation plan view. HBIM Charterhouse of Jerez, phase 15 , Sisters of Bethlehem (2000-...)

However, heritage protection should not be understood just as a legal issue to deal with once the damage is done. In contrast, it should be managed as a preventive strategy in order to save the heritage values of the monument for the future. Thus, a parameter named "vulnerability" has been defined in the HBIM model to characterize the risk of losing heritage values. That concept should not be understood as equivalent to state of conservation. In fact, a built element could be perfectly preserved but extremely vulnerable because of an inadequate protection.

For the purposes of this research, four levels of vulnerability have been established:

-MAXIMUM: Imminent risk of extensive loss of significant heritage values.

•HIGH: Imminent risk of partial loss of significant heritage values.

-MEDIUM: Foreseeable risk, not exhibited

-LOW: No foreseeable risk.

According to this settings, areas with different levels of vulnerability were characterized (Figure 6).

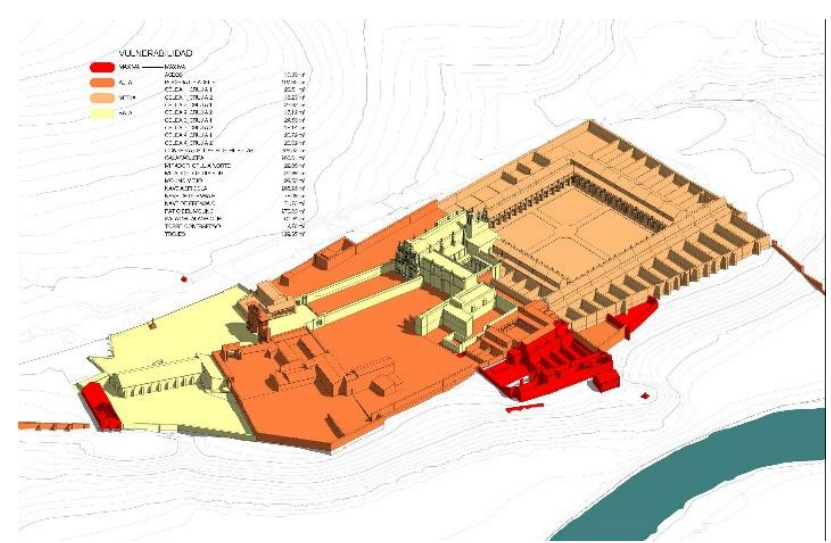

Figure 6: Vulnerability view. HBIM Charterhouse of Jerez, phase 15, Sisters of Bethlehem (2000-...) 


\subsection{Conservation}

The issue of conservation of the Charterhouse, as befits a high complex monument, has to be manage in several levels of development. This research is concerned by the preliminary diagnosis, generation of knowledge and preventive conservation and intervention planning. Thus, parameters dealing with the severity of the damages in the main structures and the urgency of the interventions were defined. For the purposes of this research, four levels of damages have been established:

- MAXIMUM: Imminent ruin.

- HIGH: Severe damages, security compromised.

- MEDIUM: Significant damages, security not compromised.

- LOW: Initial recoverable damages.

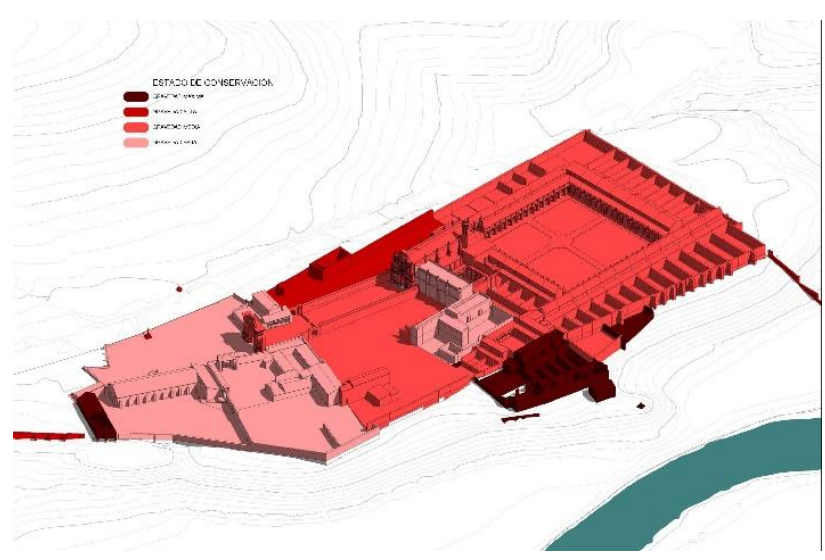

Figure 7: State of conservation: levels of damages. HBIM Charterhouse of Jerez, phase 15, Sisters of Bethlehem (2000-...)

In the same vein, four levels of urgency of intervention have been established:

- MAXIMUM: intervention required to avoid extensive irreversible ruin.

- HIGH: intervention required to avoid partial irreversible ruin.

- MEDIUM: intervention required to avoid significant damages.

- LOW: intervention required to avoid initial damages (Figure 8).

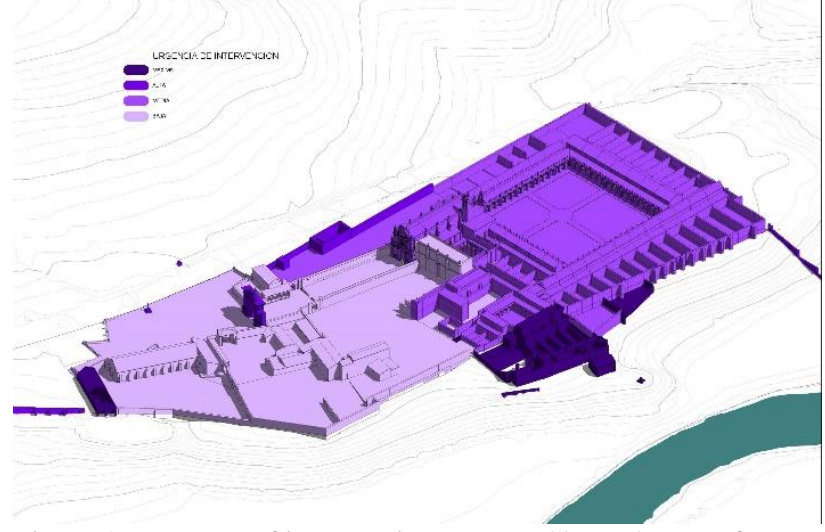

Figure 8: Urgency of intervention. HBIM Charterhouse of Jerez, phase 15, Sisters of Bethlehem (2000-...)

\subsection{Dissemination}

The issues related to dissemination, which are meagre in the Charterhouse of Jerez, have been characterized by specific parameters in the HBIM model. The issue of the limited visits to the monument has been specifically addressed. The parameter "visits" has been defined in the HBIM model with three possible settings: open, restricted, cloister (Figure 9).

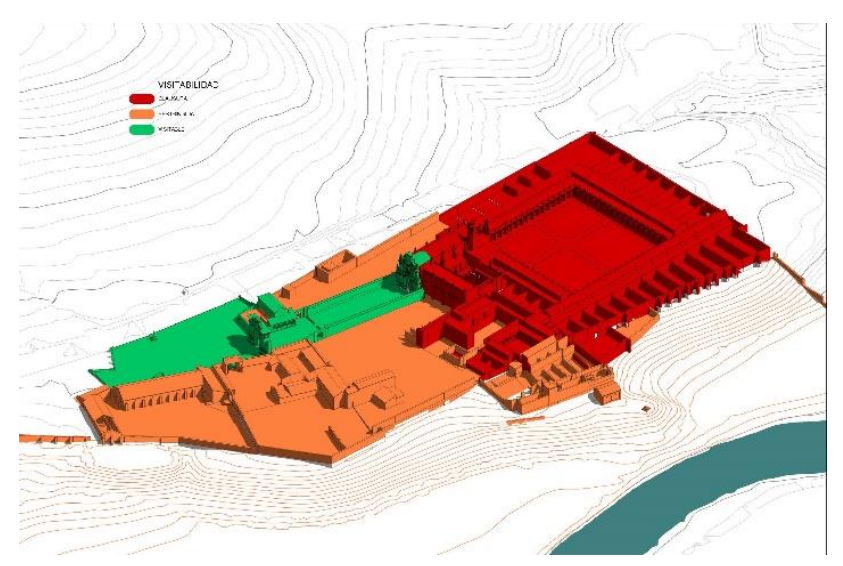

Figure 9: Visits view: open, restricted, cloister. HBIM Charterhouse of Jerez, phase 15, Sisters of Bethlehem (2000-...)

\subsection{Master Plan}

The monastery Master Plan content proposed by the PNAMC is organized in a number of blocks of information and actions plans. The blocks of information defined are: General, Documental, Immovable, Movable, Intangible and Cultural Landscape. The actions plans are Preventive Conservation, Interventions, Maintenance, Organization, Uses, Management and Dissemination. This document structure and contents is supported by the methodological resources from 20th century, still in force in many other areas, but not updated no the latest graphic and information resources in order to an efficient and sustainable management of the cultural heritage. It is justified hereunder how these blocks of information and actions plans required by the PNAMC had been addressed from the HBIM and HBIR of the Charterhouse of Jerez.

In accordance with de PNAMC, the Master Plan General Block has to contain a general description of the monument, a historical and chronological report, a previous interventions report and a legal report about the owners, easements, governance system, privileges, legacies, foundations, etc. This information is hosted in different locations in the HBIM model. The first and more generic location is "Project Information". General descriptions are included in this location, shared by the central project and every linked project, so that is the most synthetic description of the monument. Chronology and previous interventions report are not presented as closed documents, but as data base reports: open and updatable. The external data base and phase filtered HBIM views fill out those requirements. Finally, the legal report emerge from the analysis of several protection issues, hosted in the HBIR, and synthetized in a proposal of precise delimitation of the monument site and its surroundings.

In accordance with de PNAMC, the Master Plan Immovable Block must include the architectonical description of the monument, the existing documentation compilation and cataloguing, town-planning rules affecting the monument and its 
surroundings, the state of conservation and the intervention proposals, including its economic valuation. The architectonical description has been already included in the "Project Information" parameters of the HBIM model. The cataloguing and comprehensive compilation of existing documentation have been sorted out in the Heritage Building Repository HBIR, which offers not only a list of document sources but a digital structure to optimize the access and consultation. Town-planning rules affecting the monument and its surroundings has also its specific location in HBIR. In addition, a general diagnostic of the state of conservation and intervention urgency has been made. Its results have been expressed in plan and schedules views, directly obtained from the HBIM model. The economic valuation of intervention proposals falls outside the scope of this work. Nevertheless, it is possible to address an economic estimate based on the data from the HBIM model: crossing surface area with state of conservation and applying generic cost modules according to the damages degree.

Movable and Intangible Blocks required by the PNAMC have been taking into account in the general methodology, but its development have been postponed to future research. Documental and Bibliographic Block associated with the monument is solved in the HBIR, where every single reference, most of them detached from it and dispersed in different locations, is identified and described.

Cultural Landscape Block have been also analysed, as the monument has been considered an indissoluble part of it. However, BIM models are appropriate for architectonical scale as GIS models are for territorial scale. A comprehensive and efficient heritage management requires the connexion between BIM and GIS, so that is a challenge for future research.

In relation to Intervention Plans, the HBIM model offers the basic information to be defined. The information structure associated with the model includes two significant parameters on this matter: "Intervention urgency" and "Vulnerability". Graphical and alphanumerical outputs have been produced to characterize those issues in the Charterhouse of Jerez. Development of HBIM model to higher Levels of Knowledge should enable a more accurate identification and risk assessment, in order to produce preventive conservation and intervention plans on immovable, movable and ethnographic heritage. Furthermore, the parameters which should enable a periodic maintenance plan have been characterized, pending the specific studies on procedures, technical and human resources and economic valuation.

In relation to Dissemination Plan, coordination of all the stakeholders is required to deal with the issue of public visit but also dissemination activities, use management and communication media strategies.

Planimetric and photographic documentation required for the Master Plan by the PNAMC is a clear example of the methodological obsolescence of this type of documents. The investments required to produce these planimetric and photographic documents is inefficient if they are not associated to updatable and accessible tools for all agents involved. In this regard, the planimetric output from a unique HBIM model ensures updatable and consistent information. Document management tools should change photographic descriptive reports into a more efficient tool, enabling metadata labelling of photographical collections and specialized searches.

\section{CONCLUSIONS}

Heritage Building Information Modelling HBIM enhance the strategic planning of large monuments ensembles. HBIM model of the Charterhouse of Jerez (Cádiz, Spain), developed with a Level of Knowledge LOK200, provides appropriate alphanumerical and graphical outputs for strategic decisionmaking on the major guidelines of heritage management: research, protection, conservation and dissemination.

The bases for a Master Plan of the Charterhouse of Jerez have taken into account the information content required by the Spanish National Plan on Abbeys, Monasteries and Convents. Nevertheless, its specifications have been critically reviewed in order to the new technological resources, which are opening new ways for heritage management.

\section{ACKNOWLEDGEMENTS}

The authors would like to thank to the help from colleagues involved in the Late Gothic Network Consortium, the Andalusian Institute of Historic Heritage, IAPH, and the research group HUM799 Strategies for a heritage knowledge.

This investigation forms part of Project HAR2016-78113-R of the National Research, Development and Innovation Programme Aimed at the Challenges of Society sponsored by the Ministry of Economy and Competitiveness of Spain.

\section{REFERENCES}

Angulo Fornos, R., 2009: Elaboración de una base gráfica para un sistema de información y gestión del patrimonio arquitectónico: Casa de Hylas (Conjunto Arqueológico de Itálica). Universidad de Sevilla.

Aubin, P.F., 2013: Renaissance Revit: creating classical architecture with modern software. G3B Press.

Brusaporci, S., 2015: Handbook of Research on Emerging Digital Tools for Architectural Surveying, Modelling, and Representation. IGI Global.

Castellano Román, M., 2013: Hacia el Modelado de Información Patrimonial. Generación de modelos de información del patrimonio inmueble en el momento de su protección jurídica. Virtual Archaeology Review 4(9), 7-13.

Castellano Román, M., Pinto Puerto, F., n.d.: Dimensions and Levels of Knowledge in Heritage Building Information Modelling, HBIM: the model of the Charterhouse of Jerez (Cádiz, Spain).

Garagnani, S., Manferdini, A., 2013: Parametric accuracy: Building Information Modeling process applied to the cultural heritage preservation. International Archives of the Photogrammetry, Remote Sensing and Spatial Information Sciences XL-5/W1, 87-92.

González Rodríguez, R., 2008: Carta Arqueológica de Jerez de la Frontera. Consejería de Cultura de la Junta de Andalucía.

López-Menchero, V.M., Grande, A., 2011: Hacia una Carta Internacional de Arqueología Virtual. El Borrador SEAV. Virtual Archaeology Review 2, 71-75. 
Murphy, M., Mcgovern, E., Pavia, S., 2011: Historic Building Information Modelling: Adding intelligence to laser and image based surveys of European classical architecture. International Archives of the Photogrammetry, Remote Sensing and Spatial Information Sciences XXXVIII-5, 1-7.

Pinto, F., Angulo, R., Castellano, M., Guerrero, J.M., Pastor, F., 2011: Construcción de una base cartográfica activa para el conjunto arqueológico de Itálica. $P h 77,116-119$.

Pinto, F., Angulo, R., Castellano, M., Guerrero, J.M., Pastor, F., 2010: Aplicación de los sistemas BIM a la gestión de conjuntos arqueológicos: Itálica. Congreso Nacional de Investigación Aplicada a La Gestión de La Edificación, 116-133.

Rua, H., Gil, A., 2014: Automation in heritage - Parametric and associative design strategies to model inaccessible monuments: The case-study of eighteenth-century Lisbon Águas Livres Aqueduct. Digital Applications in Archaeology and Cultural Heritage 1, 82-91. 